\title{
Design and Implemention of ADC Implanted in 10000 Frame/s High-Speed CMOS Sensor
}

\author{
Eri Prasetyo Wibowo, Hamzah Affandi, Boesono Soerowirdjo, B. Heruseto, Purnawarman Musa, and \\ Michel Paindavoine
}

\begin{abstract}
This paper describes the design of pipeline ADC embedded in a high speed CMOS sensor that has been designed and fabricated by Paindavoine. The idea of ADC to be embedded in the high speed cmos sensor in order to reduce power, integrated so that the output of the CMOS sensor is already in digital form. An ADC is designed using Pipeline topology with considerations is simple in the design because it just makes a stage and the next stage is duplicated, relatively high speed and have good resolution. Pipeline ADC designed using $0.35 \mu \mathrm{m}$ CMOS technology. Pipeline ADC successfully implemented in a electronics circuit and layout. It has been fabricated. The results of simulations show that the design of pipeline ADC is working properly and can be used to handle a high speed CMOS sensor that has speed of 10000 frames/s.
\end{abstract}

Index Terms-ADC, CMOS, high speed, pipeline. frame

\section{INTRODUCTION}

Recently, improvements in the field of digital imaging world have been growing with two main image sensor technologies, namely, charge-coupled devices (CCD) and CMOS sensors. The continuous advances in CMOS technology for processors and DRAMs have made CMOS sensor arrays became alternative to the popular CCD sensors. New technologies provide the potential for integrating a significant amount of VLSI into a single chip, thereby, greatly reducing the cost, power consumption and size of the camera [1]-[4].

CMOS has major advantages in its management that can be incorporated with the sensor and converter level design. This indicates that CMOS has potential opportunities in the ease of design on a single chip, which is frequently termed as System on Chip (SoC).

As integrated circuits (IC) keep scaling down following Moore's Law, recent trends show a significant number of papers discussing the design of digital pixels [5]-[8] This

Manuscript received October 14, 2012; revised November 15, 2012. This work has been founded by Indonesian Higher Education, Contract No. 154/SP2H/PL/DITLITABMAS/III//2012

Eri Prasetyo Wibowo is with Gunadarma University, Jakarta Indonesia (e-mail: eri@staff.gunadarma.ac.id)

Hamzah Affandi and Boesono Soerowirdjo are with the Electrical engineering Dept. of Gunadarma University, Jakarta Indonesia (e-mail: hamzah@staff.gunadarma.ac.id, busono@staff.gunadarma.ac.id)

Brahmantyo Heruseto is with Computer System Dept. of Gunadarma University, Jakarta Indonesia (e-mail: brahm@staff.gunadarma.ac.id)

Michel Paindavoine is with Burgundy University, France.

Purnawarman Musa is with Burgundy University France and Gunadarma University, Jakarta Indonesia (e-mail: p_musa@staff.gunadarma.ac.id) trend is mainly motivated by the advantages of pixel-level analog-to-digital (A/D) converter such as high SNR, lower power consumption, and very low conversion speeds. Nevertheless, the resulting implementations of in-pixel analog-to-digital converter (ADC) are rather area consuming, strongly restricting the image processing capability of CMOS sensors.

A preliminary experiment for testing the CMOS sensor has been conducted by Michel Paindavoine et.al [9], [10]. In the experiment, an external ADC was used as data converter to input the FPGA. The test system is illustrated in Fig. 1.

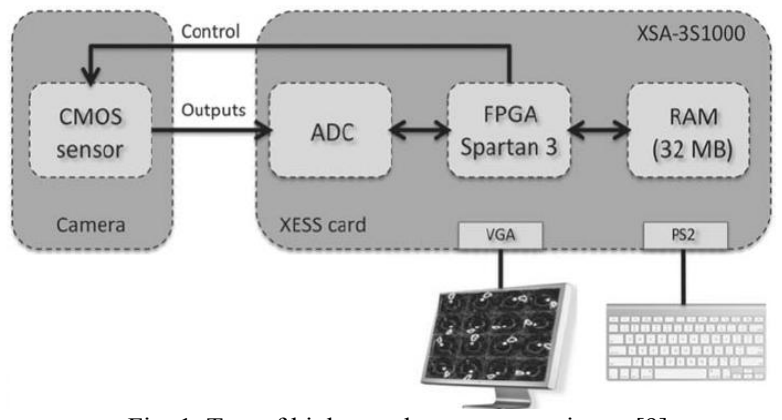

Fig. 1. Test of high speed camera experiment [9]

In the figure, the $\mathrm{ADC}$ was separated from CMOS sensor. In the next experiment CMOS sensor and $\mathrm{ADC}$ are designed and fabricated in the same single chip but independent of one another to facilitate the testing. The concept of this embedded ADC design is given in Fig. 2. The chip to be designed is illustrated at the most left of the figure.

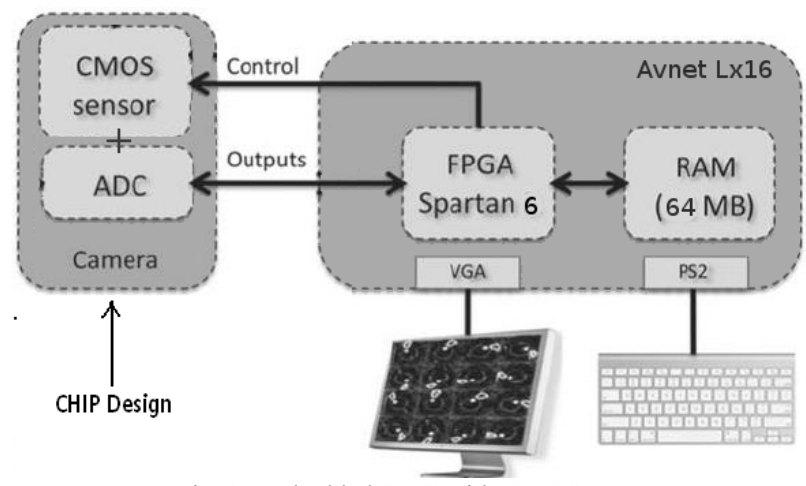

Fig. 2. Embedded ADC with CMOS sensor

This paper focuses on the design of ADC. It describes the acquisition system in parallel columns of pixels so that the speed of the acquisition up to $1.5625 \mu$ s per row $(100 \mu \mathrm{s} / 64)$ or, approximately, 10,000 frames/second could be achieved. Further design and fabrication of the ADC is aimed to fulfill the above specification, i.e., to support high-speed sensor 
with conversion rate at 10,000 frames/second and minimum resolution of 8 bits. Pipeline type of the ADC has been carefully justified, and simulated using CAD software in the $0.35 \mu \mathrm{m}$ CMOS technology.

\section{Global Design}

Before discussing the design of electronics circuit pipeline $\mathrm{ADC}$, we will describe global design layout photograph, as is shown in Fig. 3. In the photograph, there are two separate designs. The first design is a high speed CMOS sensor containing a series of a $64 \times 64$ image sensor. The design also includes Linear and Non-linear analog processing unit in focal-plane. This design is carried out by a team of Universite de Bourgogne. On the other hand, the second part of the design is an 8 bits pipeline ADC, which is done by a team of Gunadarma University. The layout size of the sensor design is $8.99 \mathrm{~mm} 2$. While the size of 8 bits pipeline ADC would occupy $1 \mathrm{~mm}$ x $0.800 \mu \mathrm{m}(1000 \mu \mathrm{m} \times 800 \mu \mathrm{m})$ and consisting of 734 transistors 49 poly-silicon capacitors.

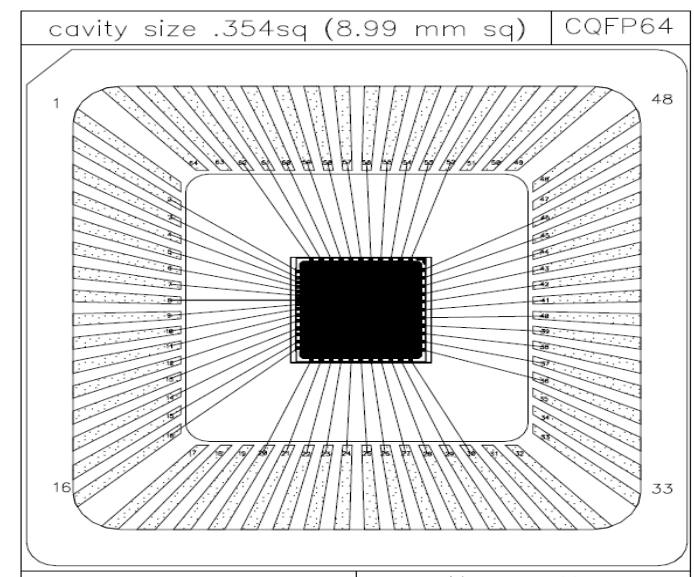

Fig. 3. Layout design of CHIP

The chip was designed and implemented using a 64 pins with CQFP64 models. Fig. 4 shows PINs designation of both designs.

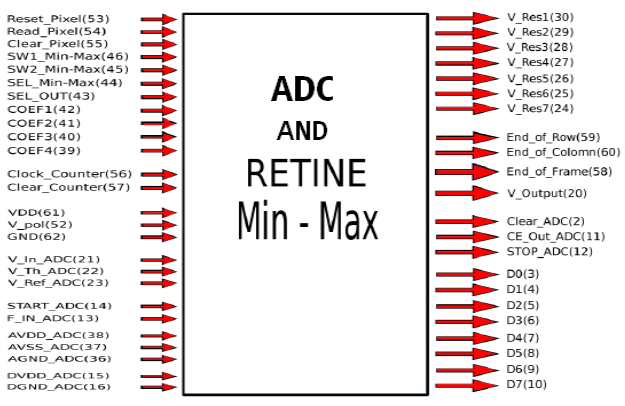

Fig. 4. The pin block global of Circuit

\section{Circuit OF PIPELINE ADC DESIGN}

Block design of pipeline ADC is shown Fig. 5, composed of 8 stages with 1-bit/stage topology. Topology of 1-bit per stage requires some supporting components, namely, Op-Amp, Comparator, DAC (reference) and switch capacitor (SC). The principle of pipeline is a step process. Therefore, 8 bit ADC requires 8 stages synchronous digital outputs by employing 8 units delay circuit (D-FF). Clock is also needed to generate the $\mathrm{ADC}$ and the pulse delay unit (D-FF).

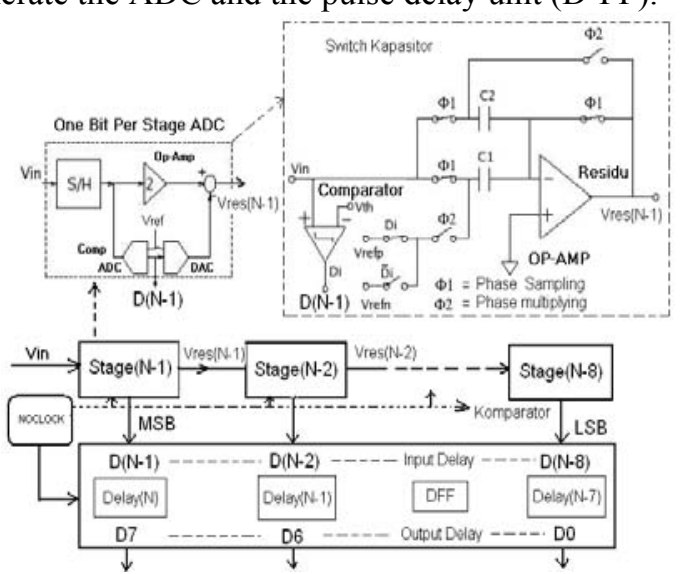

Fig. 5. Diagram block of 8 bits pipeline ADC 80 MSPS

The operation of the circuit is given in the following. If a DC input voltage Vin and frequency fin enters stage (N-1) in Fig. 5, the voltage is then sampled and held $(\mathrm{S} / \mathrm{H})$ at a sampling frequency ( $\mathrm{fs}>2 \mathrm{fin}$ ). For $\mathrm{fs}=80 \mathrm{MHz}$, (equivalent to $12.5 \mathrm{~ns}$ ), the sampling period would be $6.25 \mathrm{~ns}$ and the hold time is $6.25 \mathrm{~ns}$. During the hold time of $6.25 \mathrm{~ns}$, input signal is sampled and stored in the capacitor.

During the 2nd period of the sampling, the capacitor will charge and its voltage rises to the sampled voltage value Vin (Ф1). At the same time, the sampling voltage Vin is compared to a threshold voltage Vth. If Vin is higher than Vth, the output of the ADC will be at high level $(=1)$. On the other hand, if Vin is lower than Vth, the ADC output will be low $(=0)$. The completion of the sampling process will then be followed by multiplying process (Ф2) to obtain a residual voltage (Vres), which is required as input to the next stage.

If the digital value $(\mathrm{Di})=1$, then the value of residue is

$$
\operatorname{Vres}(i)=2 x \operatorname{Vin}(i)-\text { DiVrefp }
$$

If digital value $(\mathrm{Di})=0$, residual voltage is

$$
\operatorname{Vres}(i)=2 x \operatorname{Vin}(i)-\text { Di.Vrefn }
$$

where value of Vrefp $=2 \mathrm{~V}$ th and $V r e f n=0 \mathrm{~V}$.

Fig. 6 is the elaboration of Fig. 5. The figure shows the design of 8-bits 80 MSPS pipeline ADC with 1 bit / stage topology.

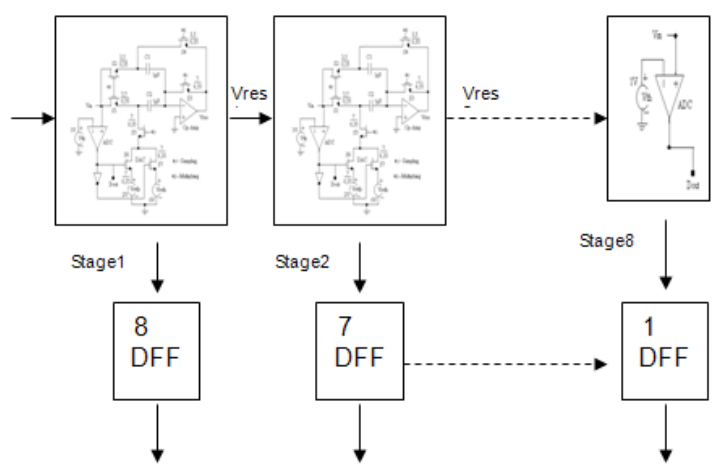

Fig. 6. Diagram block of 8-bits, 80 MSPS pipeline ADC circuit.

An 8-bits ADC requires 7 complete stages and 1 stage 
comparator. Serial connection of the stages requires time delay circuit at each stage in order to produce output (Dout) in a parallel manner. By giving Vin from $0 \mathrm{~V}$ to $2 \mathrm{~V}$ with $V t h=$ $1 \mathrm{~V}$, Vrefp $=2 \mathrm{~V}$ and Vrefn $=0 \mathrm{~V}$, in which a given clock 256 the sampling time and multiplying. So that the length of time the conversion from $0 \mathrm{~V}$ to $2 \mathrm{~V}$ is $12.5 \mathrm{~ns} \times 256=3.2 \mathrm{uS}$. With 1 step $=2 \mathrm{~V} / 256=7.8125 \mathrm{mV}$ and $\mathrm{DNL}=1 / 2 \mathrm{LSB}=3.9 \mathrm{mV}$.

A number of 36 pieces of positive edge-trigger D-FF are used for the delay-time circuit. If one D-FF consumes $200 \mu \mathrm{W}$, it needs a total power consumption of only $7.2 \mathrm{~mW}$.

\section{LAYOUT OF PIPELINE ADC DESIGN}

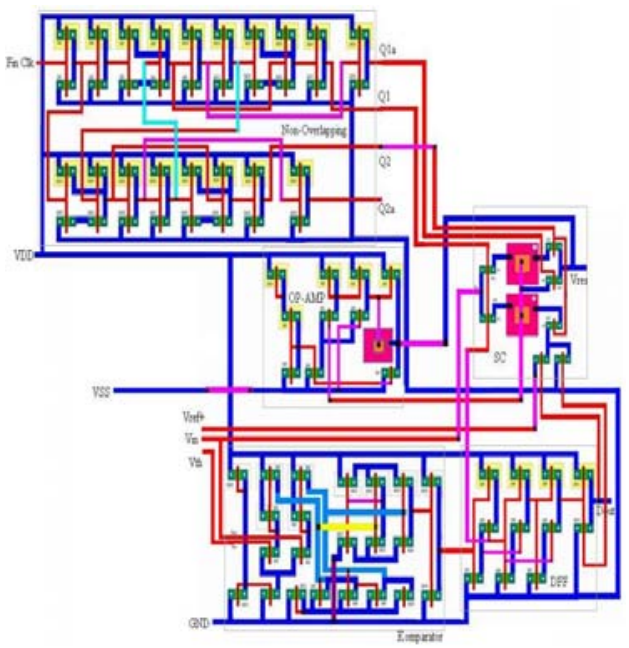

Fig. 7. Lay-out design of 1 bit/stage Pipeline ADC

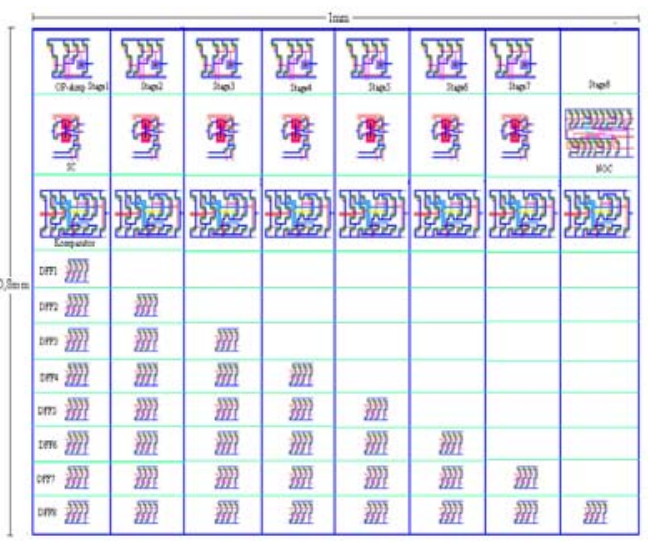

Fig. 8. Lay-out design of 8-bit pipeline ADC

Design of the layout of the ADC is implemented using the library from $0.35 \mu \mathrm{m}$ AMS technology which exploits 4 metals for components interconnection. Figure 7 is a draft of 1-bit/stage ADC layout which, totally, occupies $280 \mu \mathrm{m} x$ $500 \mu \mathrm{m}$ area. As shown in the figure, the layout consists of 3 different parts as of the followings. The top part, which is the non-overlapping clock generator, occupies an area of $280 \mu \mathrm{m}$ $\mathrm{x} 125 \mu \mathrm{m}$. A clock circuit is designed to drive the 7 stages and 1 stage SHA. The middle part of the layout consists of a series of op-amp and switch capacitors having $280 \mu \mathrm{m} \mathrm{x}$ $250 \mu \mathrm{m}$ area. This part occupies the largest area due to 3 poly capacitors sitting in it. The bottom part comprises of a unit that contains the comparator $\mathrm{ADC}$ and latches to create digital output Dout, with an area of $280 \mu \mathrm{m} \times 125 \mu \mathrm{m}$. The bottom part comprises of a unit that contains the comparator $\mathrm{ADC}$ and latches to create digital output Dout, with an area of
$280 \mu \mathrm{m} \times 125 \mu \mathrm{m}$.

The complete layout of the 8 bits pipeline ADC is seen in Fig. 8. It consists of 734 transistors and 49 poly capacitors. The area occupied for the ADC is $1000 \mu \mathrm{m} \times 800 \mu \mathrm{m}$.

\section{Simulation Results}

A series of simulations is carried out on both the electronic circuits design as well as on the layout design. For the electronic circuit, simulation is experimented to the one-bit ADC as well as to the 8 bit ADC. Simulation to one-bit ADC is important and intended to check the accuracy of the resulting residual values, which will be inputted to the next state.

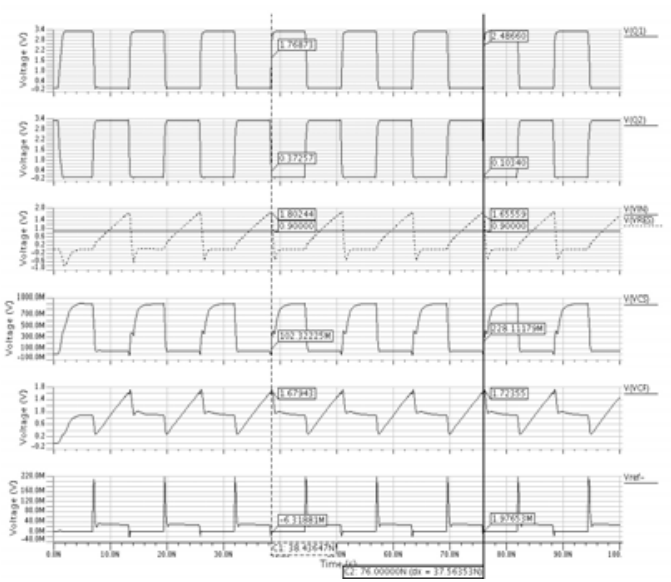

Fig. 9. Simulation results of 1 bit $\mathrm{ADC}$ with $\mathrm{VIN}=0.9 \mathrm{~V}$

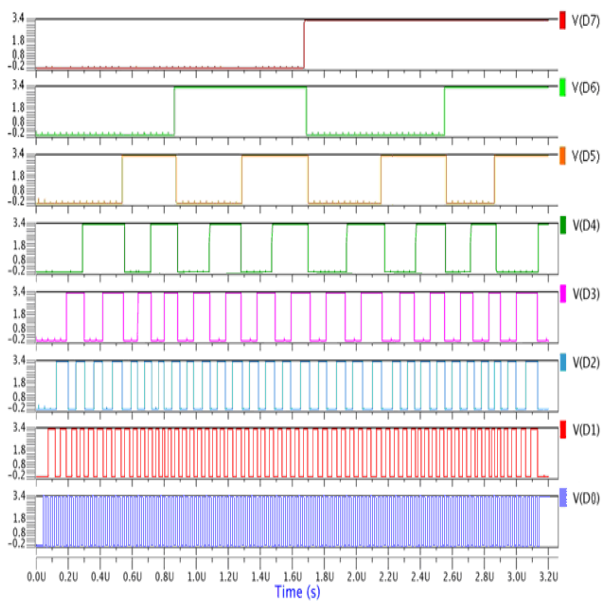

Fig. 10. Simulation of digital pipeline 8-bits ADC.

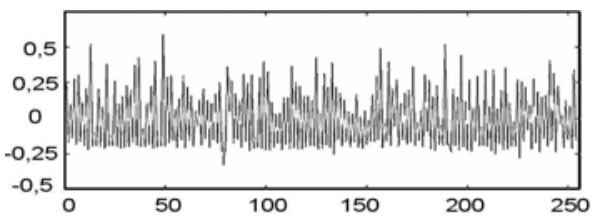

Fig. 11. DNL with $\pm 0,6 \mathrm{LSB}$

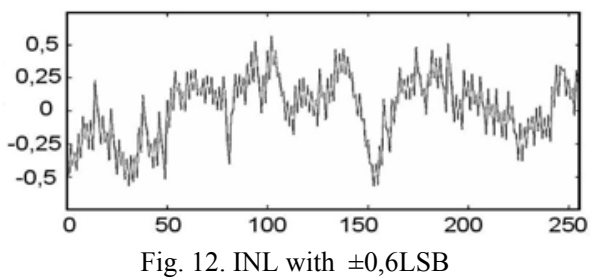


Fig. 9 shows the result of one-bit ADC simulation. With Vin $=0,9 \mathrm{~V}$, the resulted value Vres at the ADC output is $1,80244 \mathrm{~V}$. Calculated residual value Vres for the same Vin would be $2.44 \mathrm{mV}$. The difference between Vin value resulted from simulation and from calculation indicates an error of $0.24 \%$. The next simulation is to examine the digital output of 8-bits ADC. The simulation is done by varying Vin from $0 \mathrm{~V}$ to $2 \mathrm{~V}$ where result of simulation can be seen at figure 10. These simulation to see the length of time the conversion and the error of each bit digital output that occurs. Analog input is given from $0 \mathrm{~V}$ until $2 \mathrm{~V}$ and a clock time it takes the length of $12.5 \mathrm{~ns}$ so conversion time is $3.2 \mathrm{uS}(12.5$ ns $x$ 256). Suppose the input signal of $1.2 \mathrm{~V}$ and the resulting digital signal $(10,011,001)$ error occurs $153 \times 7.8125 \mathrm{mV}=$ $1.195 \mathrm{~V}$ difference with $1.2 \mathrm{~V}$ input signal there is $5 \mathrm{mV}( \pm$ $0.6 \mathrm{LSB})$. To convert the analog signal $1.2 \mathrm{~V}$ takes time $(12.5$ ns $\mathrm{x} 8 \mathrm{stage} / 2$ phase $=50 \mathrm{~ns})$, this ADC pipeline are eligible when each a pixel sensor has time of $100 \mathrm{~ns}(\mathrm{Fs}=2 \mathrm{Fin})$. With speed cameras 10,000 frames / $\mathrm{s}$, each a frame comes is required $100 \mathrm{us}$, the method of reading the required time 100 $\mu \mathrm{s} / 64$-row $=1.5625 \mu \mathrm{s} / \mathrm{row}$, so an $\mathrm{ADC}$ is given conversion time of $1.5625 \mu \mathrm{s}$. 8-bit pipeline ADC takes $50 \mathrm{nS} / 1$-input analog conversion. Simulation results are shown in figure 10 , a pipeline $\mathrm{ADC}$ has long conversion $3.2 \mathrm{uS}$ (analog pixel signals of $0 \mathrm{~V}$ to $2 \mathrm{~V}$ ) and this is enough to accommodate input from a camera with speed of 10000 frames / s $(100 \mu \mathrm{s} / 64)$.

From Simulation results of 8 bits ADC as shown in figure 10 , can be calculated error value (error) of DNL and INL , the magnitude are $\pm 0.6 \mathrm{LSB}$. DNL and INL values shown in Fig. 11 and 12 .

\section{CONCLUSIONS}

8 bits pipeline ADC successfully designed over speed of $80 \mathrm{MSPS}$, so it is able to convert the output of high speed CMOS sensor has a speed of 10000 frames / s.

The simulation results shown that the pipeline ADC worked very good, it was expressed with a small residual error and the digital error are 0.6 INL and 0.6 DNL.

Pipeline ADC is designed in a layout and has been sent to the fabrication process.

8 bits Pipeline ADC is designed using 734 transistors and 49 poly capacitors. While the size of the layout is $1 \mathrm{~mm} \times 0.8$ $\mathrm{mm}$.

\section{REFERENCES}

[1] E. R. Fossum, "Active pixel sensors (APS): Are CCDs dinosaurs," in Proc. of SPIE, vol. 1900, pp. 2-14, 1992.

[2] E. R. Fossum, "CMOS image sensors: Electronic cameraon- a-chip," IEEE Transactions on Electron Devices, vol. 44, no. 10, pp. 1689-1698, 1997

[3] D. Litwiller, "CCD vs. CMOS: facts and fiction," Photonics Spectra, pp. 154-158, 2001

[4] P. Seitz, "Solid-state image sensing," Handbook of Computer Vision and Applications, vol. 1, pp. 165-222, 2000.
[5] D. Yang, B. Fowler, and A. E. Gamal, "A Nyquist-rate pixel-level ADC for CMOS image sensors," IEEE J. Solid-State Circuits, vol. 34, no. 3, pp. 348-356, Mar. 1999

[6] S. Kleinfelder, S. Lim, X. Liu, and A. E. Gamal, "A 10000 frames/s CMOS digital pixel sensor," IEEE J. Solid-State Circuits, vol. 36, no. 12, pp. 2049-2059, Dec. 2001.

[7] A. Harton, M. Ahmed, A. Beuhler, F. Castro, L. Dawson, B. Herold, G. Kujawa, K. Lee, R. Mareachen, and T. Scaminaci, "High dynamic range CMOS image sensor with pixel level ADC and in situ image enhancement," in Sensors and Camera Systems for Scientific and Industrial Applications VI. Proc. of SPIE, Mar. 2005, vol. 5677, pp. 67-77.

[8] Y. Chi, U. Mallik, E. Choi, M. Clapp, G. Gauwenberghs, and R. E. Cummings, "Cmos pixel-level ADC with change detection," in Proc. of Int. Symp. Circuits and Systems (ISCAS), May 2006, pp. 1647-1650

[9] D. Ginhac, J. Dubois, B. Heyrman, and M. Paindavoine, "A high speed programmable focal-plane SIMD vision chip," Analog Integrated Circuits and Signal Processing, vol. 65, no. 3, 2010, pp. 389-398.

[10] J. Dubois, D. Ginhac, M. Paindavoine, and B. Heyrman, "A 10000 fps CMOS Sensor with Massively Parallel Image Processing," IEEE Journal of Solid-Stae Circuits, vol.43, no. 3, March 2008.

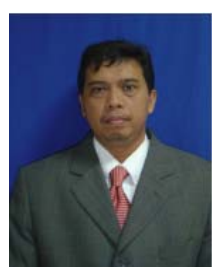

Eri Prasetyo Wibowo was born in Kendal, Indonesia, in 1966. He received the B.S degree in Electronics and Instrumentation from Gadjah Mada University, Indonesia, in 1992, the M.S. degree in Information System from Gunadarma University, Indonesia, in 1994 and the Ph.D. degree in Electronics Informatics from the Burgundy University, France, in 2005. He is member of IEEE, Professional Organization in the field of Information and Computer Technology (IPKIN) . He was as Secretary of Doctoral Program in Information Technology at Gunadarma University. He was member of EACOVIROE Project to promoted Master VIBOT which founded by Erasmus Mundus. His current interests are in Real time Image processing applications and System On CHIPs Design

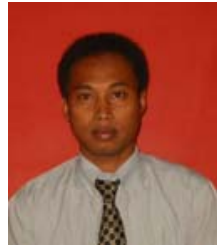

Hamzah Affandi was born in Surabaya, Indonesia in 1973. He received the B.S degree in Electrical Engineering from Gunadarma University, Indonesia, in 1998. the M.S degree in Electrical Engineering from Gunadarma University, Indonesia in 2002 and the Ph.D degree in Information Technology from Gunadarma University, Indonesia in 2009. He was as Technical Director in Megaswara TV at Bogor Indonesia and Lecturer in Gunadarma University. His current interest is in Electronics analog design.

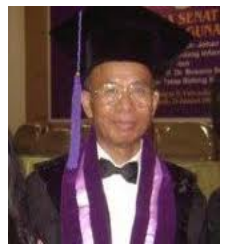

Busono Soerowirdjo was born in Purworejo, Indonesia in 1944. He received B.S degree in Electrical Engineering from ITB Bandung Indonesia in 1972. The M.S degree in Electronics design from Southampton University, England in 1975. The PhD degree in Microelectronics from Southampton University, England in 1983. He was Professor in Microelectronics from Gunadarma University. $\mathrm{He}$ was as Director of Doctoral program in Information technology at Gunadarma University Indonesia. His current interest is in Microelectronics Design.

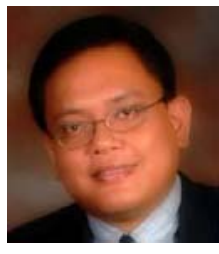

Brahmantyo Heruseto was born in 1969 . He received B.S degree in Computer Engineering from Gunadarma University, Indonesia in 1994. The M.S degree in Information Technology from Gunadarma University Indonesia in 2001 and the $\mathrm{PhD}$ degree in Information Technoloogy from Gunadarma University in 2009. He was as lecturer at Gunadarma University and he was as responsibiliity of Mentor Graphics Laboratory in Gunadarma University. His current interest is in analog neural network design. 